\title{
MEASUREMENT OF THE FADING RATE OF PAINTS
}

\author{
By Arnold J. Eickhoff and Richard S. Hunter
}

\begin{abstract}
Ability to resist fading is a valued property of most paint and textile materials, and therefore improved methods for measuring the course of fading are in demand. Two of the important evidences of the fading of paints, namely change of color and change of gloss, can be measured rapidly by photoelectric methods developed within the past few years. In the present study photoelectric tristimulus measurements of color change and photoelectric measurements of specular-gloss change were used to follow the fading of several paint samples exposed both to outdoor weather and to two machine treatments $(A$ and $B$ ) designed to weather the samples at an accelerated rate. With these measurements it was possible to compare numerically the rates of artificial and natural fading of the paints. The data which were obtained show: (1) the treatment used in conjunction with apparatus $A$ caused fading which averaged 20 times as fast as fading outdoors, but the speed-up factor varied from roughly 5 times for one paint to roughly 40 times for another; (2) the treatment used in conjunction with apparatus $B$ caused fading which averaged 5 times as fast as fading outdoors, but the speed-up factor varied from roughly 3 times for one paint to roughly 20 times for another; and (3) for almost every paint tested, the factor relating the speed of fading from treatment in apparatus $A$ to the speed outdoors was more nearly constant through the whole fading process than the corresponding factor for treatment in apparatus $B$. Thus treatment $A$ not only faded paints faster, but it provided a preview of the course of fading which was usually a better representation of outdoor fading than that provided by treatment $B$. The data collected during the present study are noteworthy chiefly for the methods they demonstrate. These should be valuable for future studies of the fading of materials and for the examination of methods for accelerating fading.
\end{abstract}

\section{CONTENTS}

I. Introduction _... 773

II. The paint finishes studied.

III. Exposure of the panels

IV. Measurement of the fading of the paint finishes........... 777

1. Daylight apparent reflectance, $Y_{\ldots} \ldots \ldots 78$

2. Chromaticity in the $(\alpha, \beta)$-coordinate system $\ldots 78$

3. Amount of color change, $\Delta E_{\ldots} \ldots 782$

4. Specular gloss, $G_{8}$

5. Lengths of exposure which cause chalking and checking ..... 786

V. The "speed-up factor" in accelerated weathering

VI. Conclusions_._.

VII. References

\section{INTRODUCTION}

The ability to maintain their original appearance in spite of exposure to radiant energy, air, and moisture is a major determinant of the value of paints, textiles, and many other manufactured materials. With paints, change of color, loss of gloss, and sometimes checking 
and chalking are the evident results of failure to resist such exposure. With many materials which suffer from exposure, change of color is the major evidence of failure. Accordingly the term fading is widely used to refer only to changes of color resulting from exposure. However, the term in the present paper applies to all changes in appearance which are caused by exposure.

The present paper describes an attempt to evaluate quantitatively the fading of a number of paints. Although methods for measuring changes in color and gloss have been in existance for a number of years, these have seldom been used to measure the extent or rate of fading. Appel [2] ${ }^{1}$ did use change of the spectral reflectance of a number of dyed fabrics to evaluate the progress of their fading and to compare the rates of fading under different exposure conditions. However, the visual method he used was not rapid and the spectral curves obtained could not be quickly converted to the magnitudes of color change in which the dye technologist is interested. Appel's methods therefore did not come into general use.

Rapid photoelectric methods for measuring gloss have become available during the past several years, and rapid methods for measuring surface-color change based on photoelectric instruments have been developed quite recently. It appeared to the authors that these methods of measurement were potentially valuable for the quantitative study of fading. The work reported below was therefore carried out to develop and demonstrate the use of photoelectric gloss and color measurements for evaluating the amount and character of fading. The ability to resist exposure of the particular paints used as examples is, in the present paper, a question of secondary interest.

In the testing of paints, textiles, and other materials which fade, widespread use is made not only of outdoor exposures, but of machine treatments which produce rapid fading. Each such treatment consists in the exposure of test samples to a strong source of radiant energy rich in the violet and ultraviolet, and usually to a water spray and to other elements designed to subject the specimen in the apparatus to the weathering forces ordinarily met in normal use. The value of these treatments depends (1) upon their faithfulness for forecasting the course of natural fading and (2) upon the rate at which the processes of fading are accomplished. The present paper suggests a method by which the rate of fading may be numerically evaluated and a method by which the faithfulness of prediction may be estimated from the numerical data. For a discussion of the problems of making accelerated-exposure tests and of interpreting their results for various types of paint finishes, one may refer to the ASTM Symposium on Correlation between Accelerated Laboratory Tests and Service Tests of Protective and Decorative Coatings [1].

\section{THE PAINT FINISHES STUDIED}

The fading of eight paint finishes was studied. Six of these finishes were prepared from oleoresinous enamels, ${ }^{2}$ chosen because the outdoor fading of finishes in this class has proved to be difficult to predict from the results of exposures in accelerated-weathering machines. The

\footnotetext{
1 Numbers in brackets indicate literature references at the end of this paper.

These six enamels were furnished by Subcommittee VII of Committee D-1, American Society for Testing Materials, during the course of a comparative study of accelerated weathering in which the National Bureau of Standards cooperated.
} 
seventh finish was a white-lead, zinc-oxide, linseed-oil mixture tinted with reduced para red (paranitraniline red toner precipitated on barium sulfate) to produce a paint which was moderate pink ${ }^{3}$ in color. This finish was chosen for a trial of the method of measuring fading because it was known to rapidly change color on exposure. The eighth paint was composed of chrome yellow and zinc oxide in linseed oil and was chosen as a typical widely used paint which is highly resistant to fading. The daylight apparent reflectance, chromaticity, and specular gloss of each of the eight finishes at the start of the test are given in table 2 , below.

The six oleoresinous enamels were produced by separately combining each of three varnish vehicles (phenolic resin, alkyd resin, and estergum resin) with two colored pigment mixtures (green and tan). Two coats of each of the resulting enamels were applied to three panels of 22-gage auto-body steel which had been sanded, washed with toluene, immersed in a phosphoric acid pickling solution, rinsed well with water, dried, and covered with one coat of a suitable primer. With the parared-linseed-oil paint, three coats were applied directly to edge-grain, red-cedar panels; and with the chrome-yellow paint, two coats were used on panels cut from black iron.

\section{EXPOSURE OF THE PANELS}

One of the three panels of each paint was exposed outdoors, one was exposed to an accelerated-weathering treatment used in conjunction with a device herein designated apparatus $A$, and the third was exposed to a somewhat different treatment used in conjunction with a second device designated apparatus $B$. In the text and legends which follow, each of the accelerated-weathering treatments is identified with the apparatus in which it was carried out. For outdoor exposure, the panels were placed in racks facing south at $45^{\circ}$ from horizontal on the top of a building at the National Bureau of Standards in Washington, D. C. The lengths and dates of outdoor exposure were as follows:

\begin{tabular}{|c|c|c|}
\hline Paint finish & $\begin{array}{l}\text { Length of } \\
\text { exposure }\end{array}$ & Dates of exposure outdoors \\
\hline $\begin{array}{l}\text { Chrome yellow and zinc oxide } \\
\text { in linseed oil. } \\
\text { White lead, zinc oxide in linseed } \\
\text { oil, tinted with para red. } \\
\text { Six oleoresinous enamels...... }\end{array}$ & $\begin{array}{l}2 \text { years } \\
38 \text { days } \\
1 \text { year }\end{array}$ & $\begin{array}{l}\text { July } 1937 \text { to June } 1939 . \\
\text { November and December } \\
\text { 1939. } \\
\text { March } 1939 \text { to February } \\
\text { 1940. }\end{array}$ \\
\hline
\end{tabular}

Each accelerated-weathering apparatus used a carbon arc as a source of radiant energy and a water spray which wet the panels at regular intervals. Neither was run continuously. Instead, operating schedules were arranged which allowed time for the inspection and measurement of the panels as well as time for their rest during each week. The operating schedule of each treatment for 1 week is shown diagrammatically in figure 1. During the 168 hours of a week,

\footnotetext{
${ }^{3}$ According to the ISCC-NBS system of color names [9].
} 
the panels in apparatus $A$ were subjected to irradiation and intermittent wetting for 81.5 hours and those in apparatus $B$ for 106.5 hours. In computing the lengths of exposure below, only the periods of actual operation of the apparatus were used.

The arc and water spray used to accelerate the break-down of paint finishes in each apparatus are described in table 1. In each apparatus a cylinder with panels mounted on the interior wall revolves slowly about the carbon-arc lamp in the center. During each rotation, a panel mounted on the cylinder wall passes the stationary water spray located inside the cylinder.
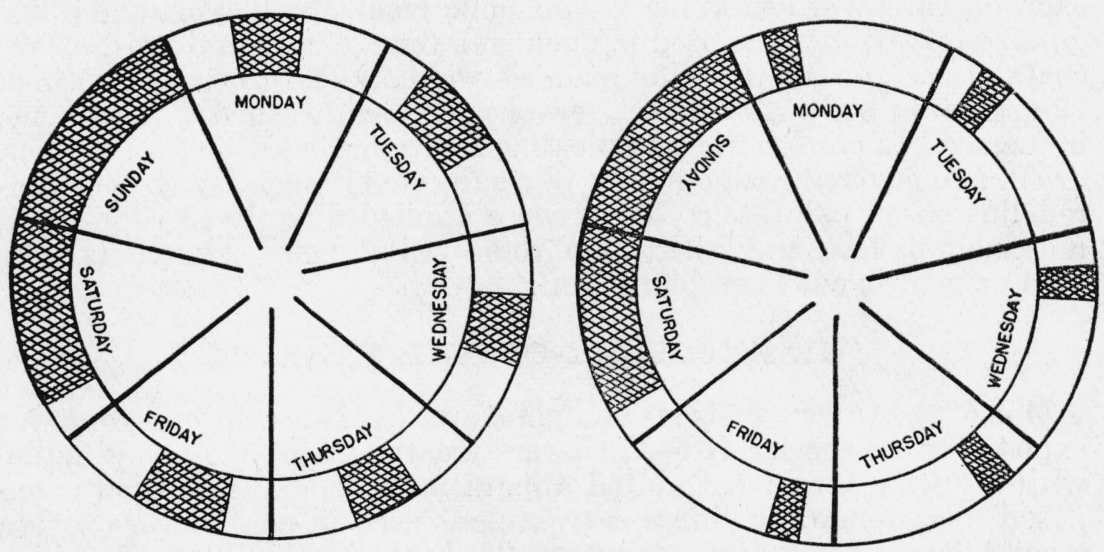

A

B

FigURe 1.-Operating schedules for apparatus $A$ and apparatus $B$ for 1 week. White areas, operation; shaded areas, rest.

TABLE 1.-Comparison of the carbon arc and water spray used in each test

\begin{tabular}{c|c|c}
\hline \hline Characteristic & $\underset{A}{\text { Apparatus }}$ & $\underset{B}{\text { Apparatus }}$ \\
\hline
\end{tabular}

CARBON ARC

Average volts

Average ampere

Average watts

Type of glass enclosing arc

Distance from are to panels, $\mathrm{cm}$

Average irradiance of panels, watts $/ \mathrm{cm}^{2}$

\begin{tabular}{r|r}
50 & 140 \\
60 & 16 \\
3,000 & 2,240 \\
Corex $D$ & Pyrex \\
45 & 38 \\
$\approx 0.061$ & $\$ 0.067$ \\
\hline
\end{tabular}

WATER SPRAY

\begin{tabular}{l|r|r}
\hline Relative pressure & Low \\
Interval between successive wettings, min & High \\
Duration of each wetting, min & 20 \\
\end{tabular}

Measured by R. Stair, of the National Bureau of Standards.

- From a report of the Pacini Laboratories dated Feb. 6, 1931. Used by permission of the Atlas Electric Devices Co. 
In figure 2 the spectral energy of the carbon arc measured through the Corex $D$ glass [11] window used in apparatus $A$ and that of the average midday sunlight estimated by Moon [10] are plotted as functions of wavelength from 200 to $700 \mathrm{~m} \mu$. Unfortunately the spectral distribution of the arc used in apparatus $B$ was not available for comparison in this figure.

Although the average irradiance of the panels under midday sun was probably higher (roughly $0.075 \mathrm{watt} / \mathrm{cm}^{2}$ is suggested by Moon [10]) than that of the panels under either of the ares, this higher irradiance by sunlight lasted only for short periods on each clear day. The fading of the paint panels exposed in the two machines was more rapid than that of the panels exposed outdoors, for two reasons: (1) the flux of the energy incident on the panels was at full density whenever

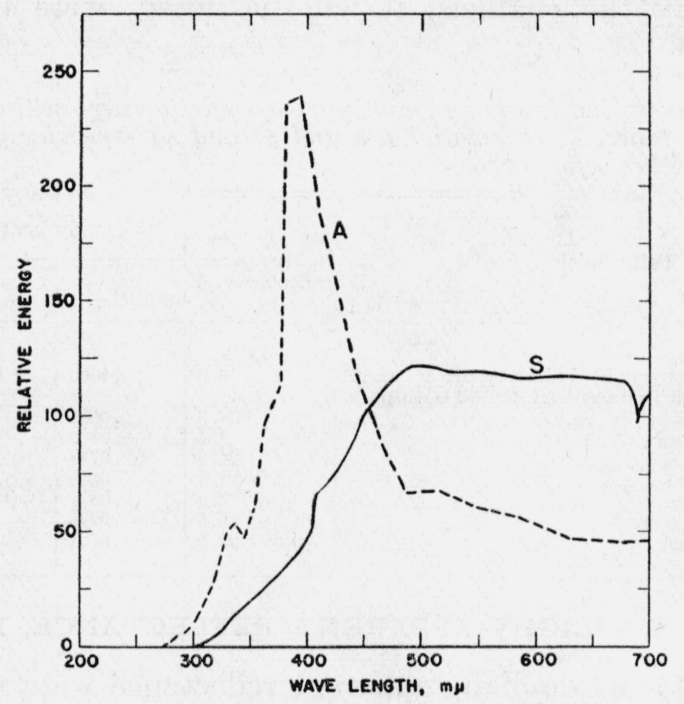

FIgURE 2.-Relative spectral energy of the arc $(A) *$ used in apparatus $A$ and estimated average midday sunlight (S) (from Moon [9] using air mass of 2.0).

the apparatus operated; and (2) the spectral energy of the sources is concentrated in the near ultraviolet and short-wave end of the visible spectrum which constitute the spectral region known to be chiefly responsible for the fading of paints. An additional factor which may have contributed materially to the rapid fading of the panels was their periodic wetting during irradiation.

\section{MEASUREMENT OF THE FADING OF THE PAINT FINISHES}

The multipurpose reflectometer [4] was used to follow the changes of the paint finishes in daylight apparent reflectance, chromaticity, and specular gloss. Reduction of these data to give chromaticity expressed in the $(\alpha, \beta)$-uniform-chromaticness-scale system has already

\footnotetext{
${ }^{*}$ Curve $A$ is reproduced by permission of the National Carbon Co., Cleveland, Ohio.
} 
been described $[5,6,13]$. Amounts of color difference, $\Delta E$, were computed according to the method described by Hunter [6].

As the working standard of apparent reflectance and chromaticity, a single white ceramic tile was used throughout the project. The working standard of specular gloss was a piece of polished black glass. Since the errors of measurement were probably of a magnitude which is not serious for evaluating fading [6], no attempt was made to correct the readings for failure of the source-filter-photocell combinations to be spectrally equivalent to the ICI standard observer [5, p. $71 ; 6]$, nor for the scale errors of the instrument [4]. The data shown graphically in the following figures represent only those measurements deemed necessary to illustrate the methods employed.

The derived values of daylight apparent reflectance, chromaticity, and specular gloss of each of the finishes before exposure are given in table 2. Only the enamels, it will be noted, were measured for specular gloss.

TABLE 2.-Values indicated by multipurpose-reflectometer settings of daylight apparent reflectance, $Y$; chromaticity, $\alpha$ and $\beta$; and $45^{\circ}$-specular gloss, $G_{s\left(45^{\circ}\right)}$; of each of the finishes before exposure.

\begin{tabular}{|c|c|c|c|c|}
\hline \multirow{2}{*}{ Paint finish } & \multirow{2}{*}{$\begin{array}{l}45^{\circ}, 0^{\circ} \text { day- } \\
\text { light apparent } \\
\text { reflectance, } Y\end{array}$} & \multicolumn{2}{|c|}{$45^{\circ}, 0^{\circ}$ chromaticity } & \multirow{2}{*}{$\begin{array}{l}\text { Specular } \\
\text { gloss, } \\
G_{s\left(45^{\circ}\right)}\end{array}$} \\
\hline & & $\alpha$ & $\beta$ & \\
\hline Chrome yellow and zinc oxide in linseed oil & $\%_{46.0}$ & 0.1060 & 0.1150 & Per mil \\
\hline White lead, zinc oxide in linseed oil, tinted with para & & & & \\
\hline Green phenolic enamel & $\begin{array}{r}38.6 \\
9.5\end{array}$ & $\begin{array}{r}.0688 \\
-.0882\end{array}$ & $\begin{array}{l}.0253 \\
.0739\end{array}$ & \\
\hline Tan phenolic enamel & 24.2 & .0748 & .0735 & 51.5 \\
\hline Green alkyd enamel & 9.0 & -.0936 & .0738 & 52.0 \\
\hline Tan alkyd enamel & 23.9 & .0672 & .0746 & 53.5 \\
\hline Green ester-gum enamel & 10.5 & -.0976 & .0759 & 54.0 \\
\hline Tan ester-gum enamel. .................... & 23.5 & .0724 & .0739 & 55.5 \\
\hline
\end{tabular}

\section{DAYLIGHT APPARENT REFLECTANCE, $Y$}

Values of $45^{\circ}, 0^{\circ}$ daylight apparent reflectance were measured for each of the painted panels as they faded. From these measured values little was found to indicate the progress of fading and even less to indicate the relative rates of fading outdoors and in the apparatus. The chrome-yellow panels, for which curves of daylight apparent reflectance are plotted as a function of hours of exposure in figure 3 , darkened in a manner which is characteristic of the paint. A number of the other paints chalked and thus turned lighter. The panels exposed outdoors collected dirt and tended to be darker than the corresponding panels exposed in the accelerated-exposure apparatus. No attempt was made to remove dirt from the panels during the course of this investigation, and for this reason a number of the panels exposed outdoors changed in daylight apparent reflectance more rapidly than the panels of the same paints exposed in either apparatus.

\section{CHROMATICITY IN THE $(\alpha, \beta)$-COORDINATE SYSTEM}

Loss of saturation (weakening of color) is ordinarily the most readily apparent evidence of fading. As would therefore be expected, 
the measurement of chromaticity yields useful data on the fading of most paint finishes. To designate chromaticity, the $(\alpha, \beta)$-coordinate system $[5,6,13]$ was chosen because it yields scales for surface colors approximately uniform in chromaticness. Thus the spacing of the points in figures 4 through 7 accords fairly well with the perceived changes in the chromaticness of the corresponding painted panels.

The most recent equations [5, 6, 13] for computing $\alpha$ and $\beta$ from tristimulus settings had not been chosen at the time the present work was started. Instead, an earlier pair of equations [3] was employed:

$$
\begin{aligned}
& \alpha=\frac{2(A-G)}{2 A+5 G+3 B}, \\
& \beta=\frac{G-B}{2 A+5 G+3 B} .
\end{aligned}
$$

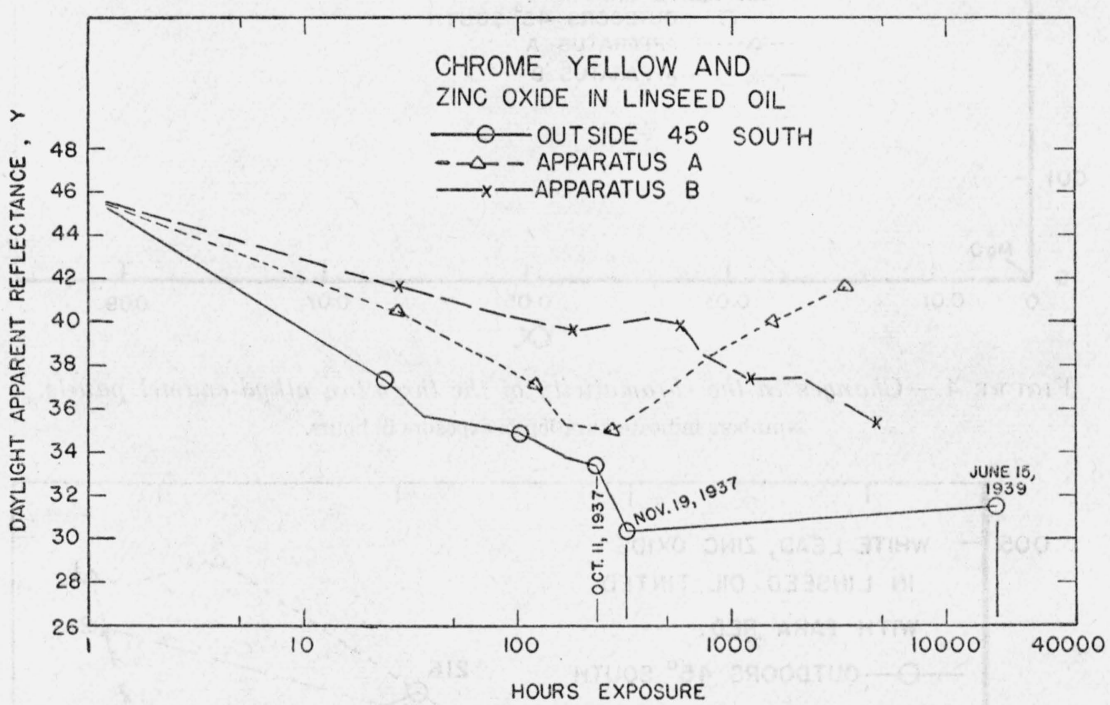

FIGURE 3.-Changes in $45^{\circ}, 0^{\circ}$ daylight apparent reflectance of the three chromeyellow panels with length of exposure.

The use of the old equations, however, does not detract from the value of the present work.

Figures 4 through 7 show the changes in the chromaticity of the panels of four of the eight paint finishes studied. Each of the graphs encloses that part of the $(\alpha, \beta)$-diagram needed to illustrate the fading of the panels represented in it. Loss of saturation is the most obvious aspect of the fading of most chromatic objects. On the $(\alpha, \beta)$-diagram, loss of saturation is represented by a vector directed toward the origin, or neutral (gray, white $\mathrm{MgO}$ ), point. Because of this correlation, Scofield [12] suggested that the "percentage fading" of a paint panel be designated the percentage decrease of the distance from the origin to the point on the $(\alpha, \beta)$-diagram representing the panel. In figures 4 through 7 the origin was included in each graph to facilitate estimates of the Scofied values of "percentage fading" by visual inspection of the graphs. 


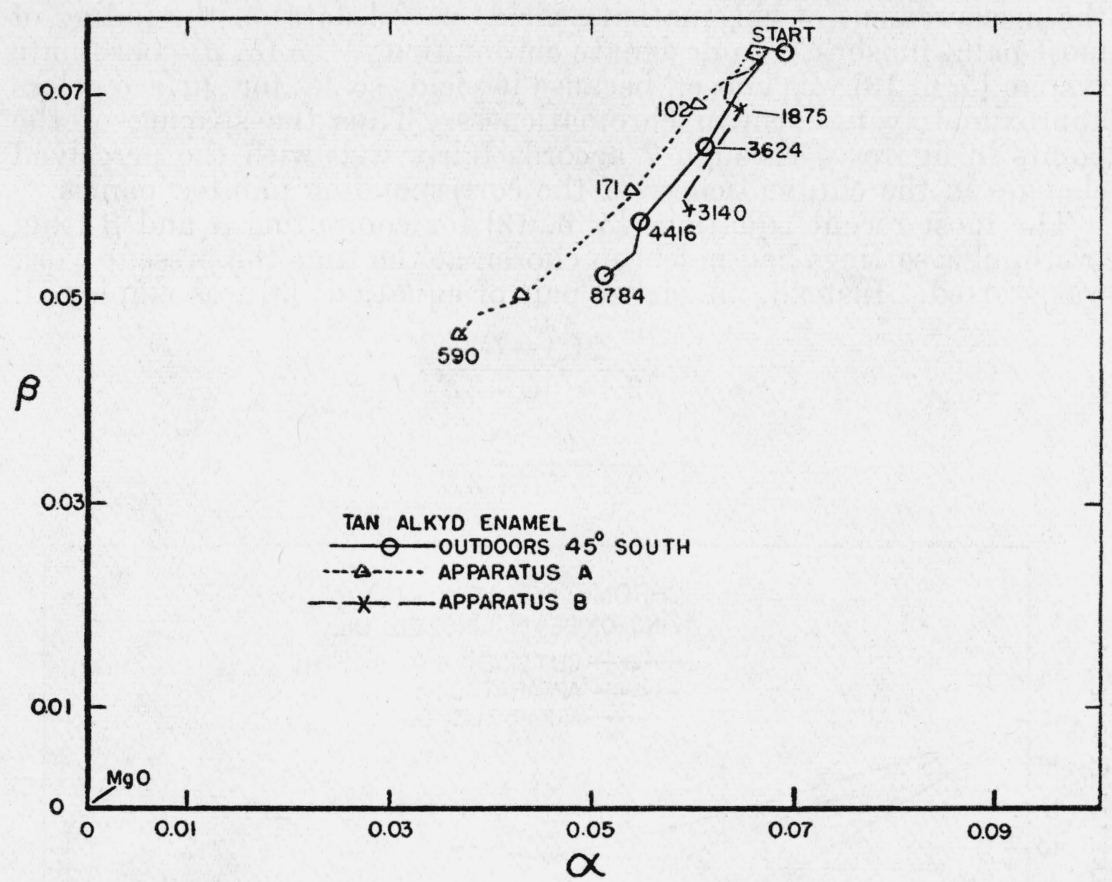

Figure 4.-Changes in the chromaticity of the three tan alkyd-enamel panels. Numbers indicate duration of exposure in hours.

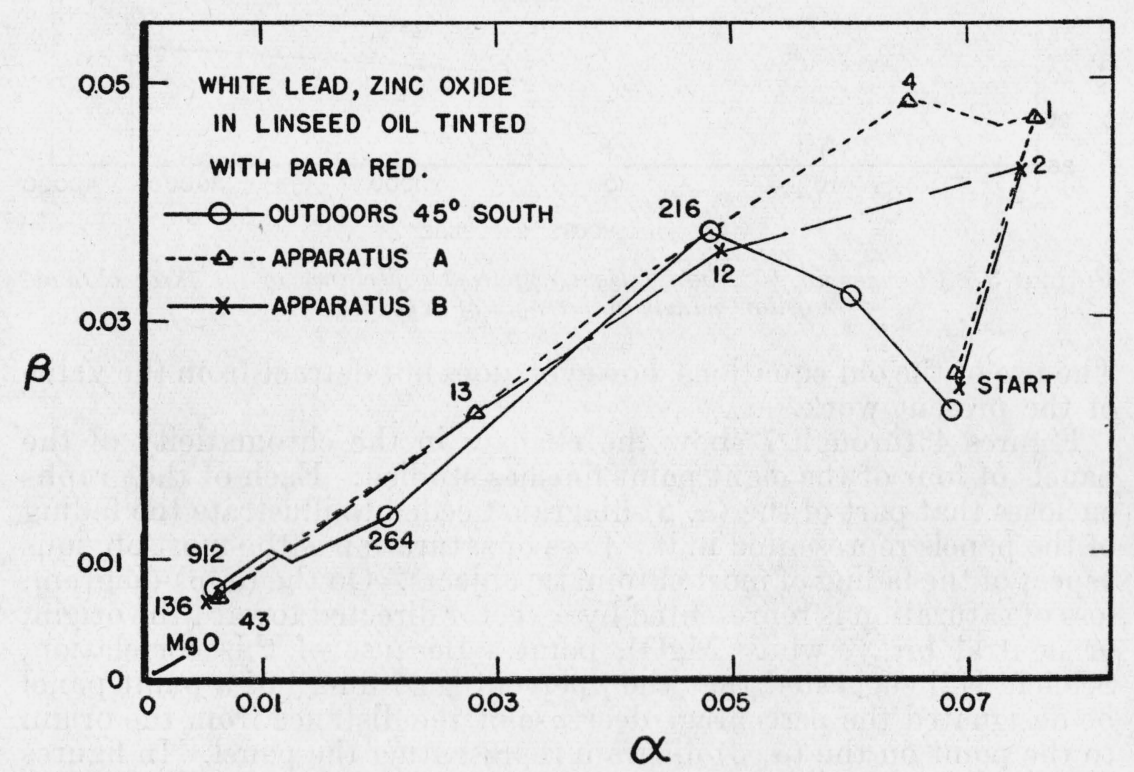

Figure 5.-Changes in the chromaticity of the three para-red tinted panels. Numbers indicate duration of exposure in hours. 
The chromaticity changes of only four of the eight paint finishes are illustrated because these four adequately demonstrate the types of change found during the present investigation. Figure 4, which shows the changes in $\alpha$ and $\beta$ due to exposure of the three tan alkydenamel panels, illustrates losses in the saturation which are typical of the fading of chromatic surfaces.

A somewhat unusual change of chromaticity during fading is shown by figure 5 , which is similar to a figure used in a previous paper

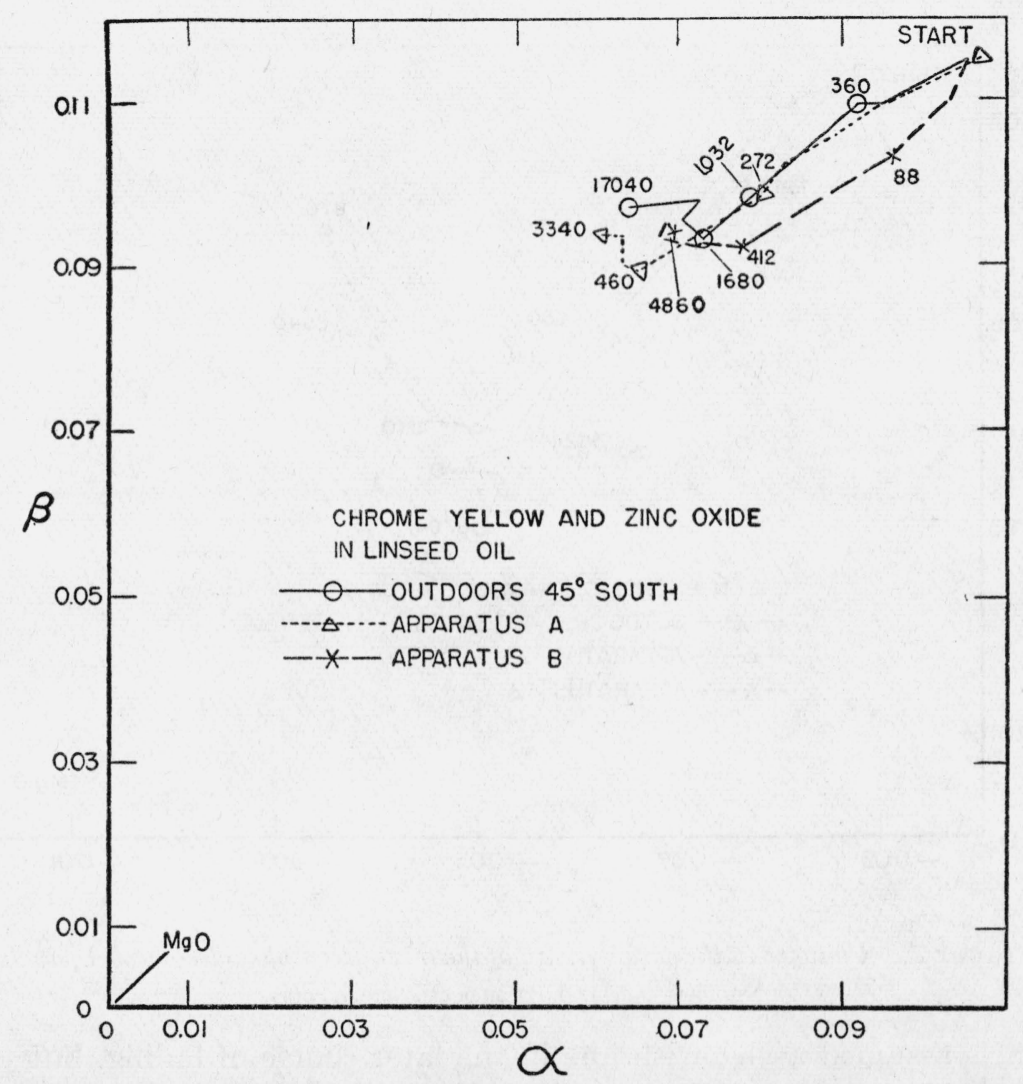

FIgURE 6.-Changes in the chromaticity of the three chrome-yellow panels. Numbers indicate duration of exposure in hours.

for the same illustrative purpose [5]. Each of the three panels coated with para-red tinted paint shifted in hue from moderate pink ${ }^{4}$ to weak orange ${ }^{4}$ during the early stages of exposure; this change of hue is represented on the $(\alpha, \beta)$-diagram by the change in the angle between the $\alpha$-axis and the line passing through the origin and the point representing the color of the painted panel. This angle is known as the hue angle [6]. During the first few hours, moreover, the two panels exposed indoors increased rather than decreased in saturation. The initial change in hue was roughly the same for each

\footnotetext{
${ }_{4}^{4}$ According to the ISCC-NBS system of color names [9].
} 
of the three panels, and after this change, fading proceeded in a typical manner. With only short periods of exposure, each of the three panels lost almost all saturation.

Excellent resistance to exposure is indicated in figure 6 by the relatively small changes of the chromaticity of the chrome-yellow panels. In figure 7 the changes in the chromaticity of the three green-phenolic panels are showr. This graph was included because it illustrates an instance in which the chromaticity change predicted by indoor exposure did not occur outdoors. In both treatments the

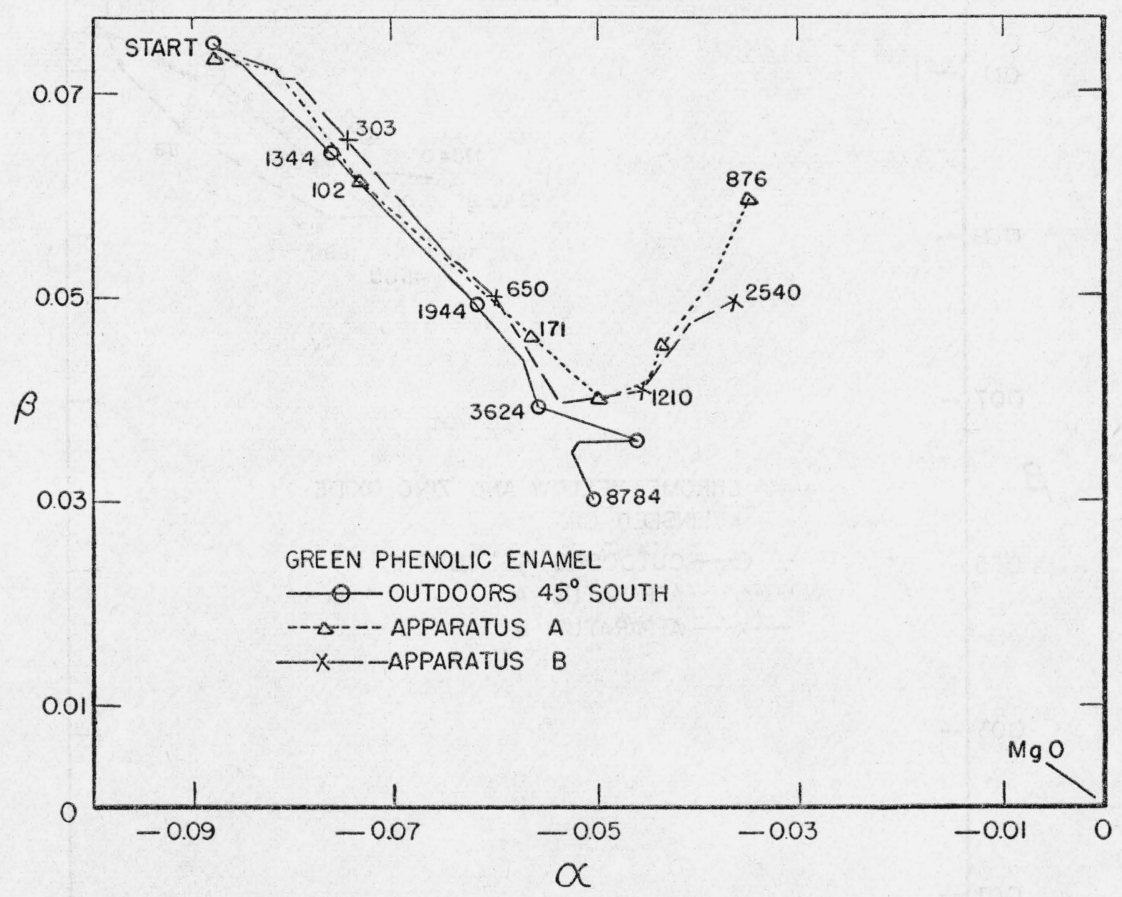

FIgURE 7.-Changes in the chromaticity of the three green phenolic-enamel panels.

Numbers indicate duration of exposure in hours.

panels assumed a yellowish hue in the later course of fading, but the panel exposed outdoors merely decreased in saturation without taking on the yellowish hue.

\section{AMOUNT OF COLOR CHANGE, $\triangle E$}

Numbers which closely correspond to perceived amount of surfacecolor change can be computed from photoelectric tristimulus data by using the equation for color difference, $\Delta E$, developed by Judd $[7,8]$ and modified by Hunter [6]. In this equation an apparent-reflectance difference and a chromaticity difference are weighted and then combined to give a measure of the resultant color difference, $\Delta E$, expressed in NBS units of color difference. The $\Delta E$ scale was designed to give good accord between computed values and perceived amounts of 
color difference; it would therefore seem logical to use the NBS unit of color difference for the measurement of fading.

The NBS unit, it may be added, was made so small that differences of less than one unit are perceptually unimportant color differences for most commercial transactions [7, p. 425]. Measured differences of more than one unit, however, represent color differences which are usually of commercial significance.

The fading of each of the panels was measured on the $\Delta E$ scale. For each occasion on which a panel was measured, the amount of change in the surface color was determined by comparing the initial readings with those just obtained. Table 3 illustrates how the values of $\Delta E$ were computed from the changing values of apparent reflectance and chromaticity of the panels.

TABLE 3.-Computation of the change from initial color of the tan phenolic panel exposed in apparatus $A$

Equation for amount of color change, $\Delta E[5,6]$ :

$$
\Delta E=\left\{\left[7 Y^{1 / 4} \sqrt{\overline{\Delta \alpha^{2}}+\overline{\Delta \beta}^{2}} \cdot 10^{2}\right]^{2}+\left[\Delta\left(Y^{1 / 2}\right) \cdot 10^{2}\right]^{2}\right\}^{1 / 2}
$$

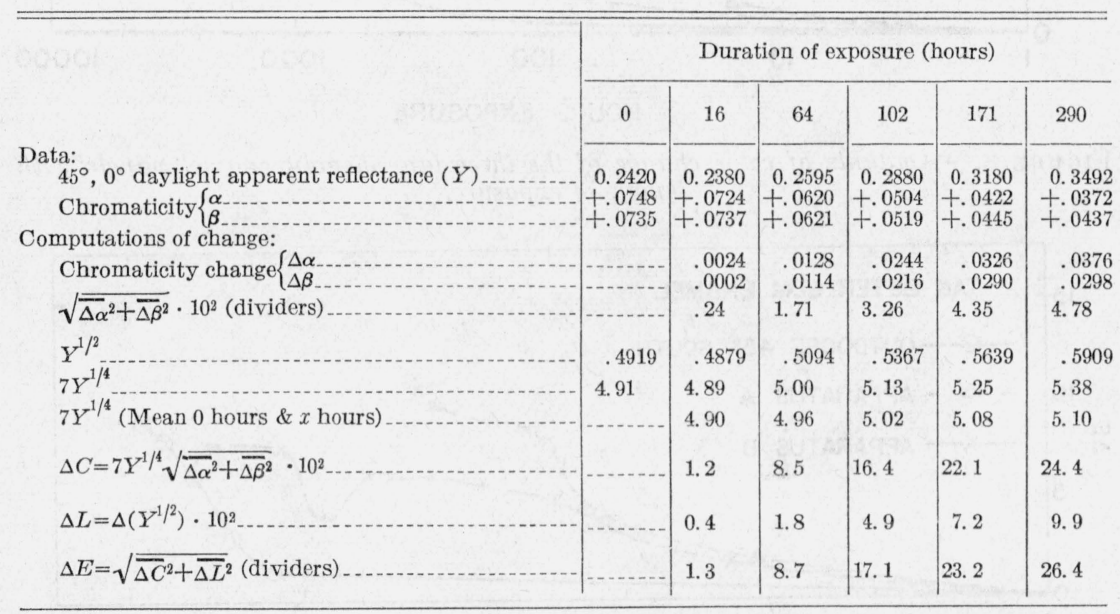

Figures 8 and 9 show graphically the color changes of two sets of panels chosen as typical of the changes in the eight sets studied. In these figures, length of exposure is measured on a logarithmic scale so that similar patterns of fading - those which differed only in the speed of fading - could be readily identified by visual inspection. By the similarity of the shapes of the three curves in figure 8, it can be deduced that the rates of color change of each of the tan phenolic panels exposed in the apparatus foretold the rate of change followed more slowly by the third panel outdoors. From the dissimilar curves for exposure outdoors and in apparatus $B$, shown in figure 9 , it is apparent that the tan ester-gum panel exposed in apparatus $B$ failed to predict the pattern of color change resulting from outdoor exposure. 


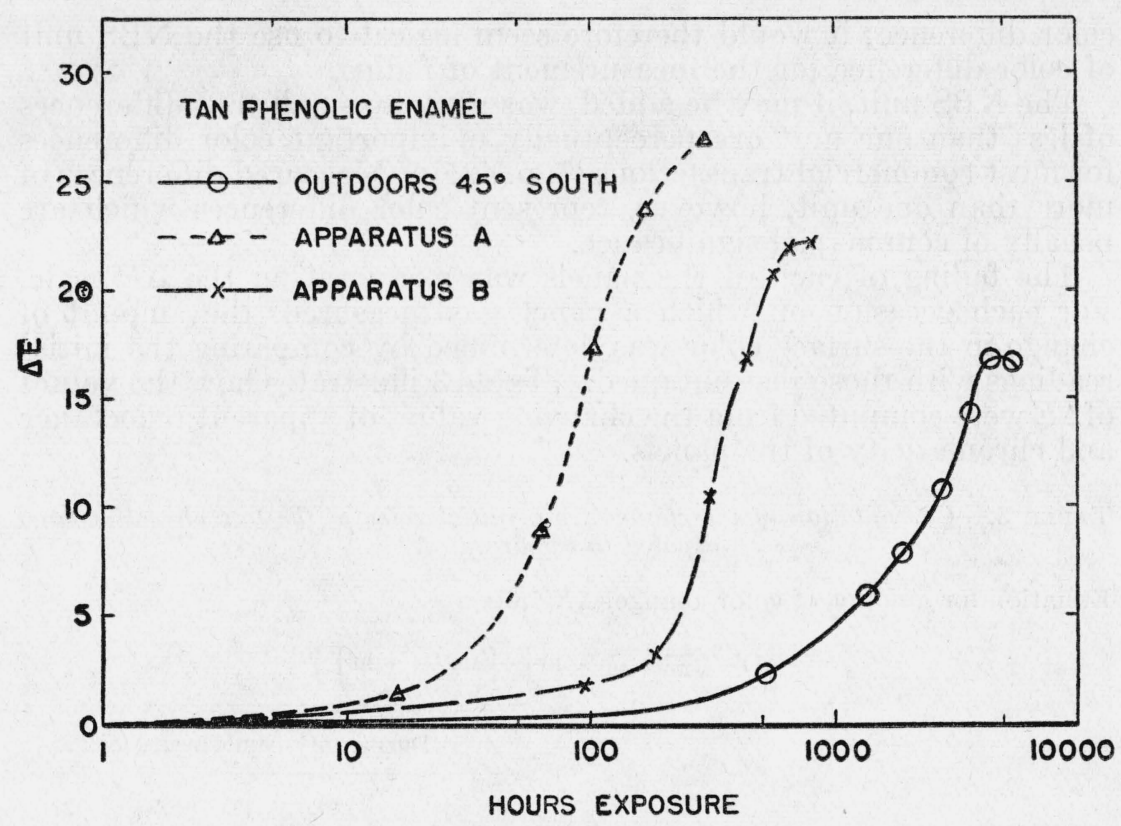

Figure 8.-Amounts of color change of the three tan phenolic-enamel panels with length of exposure.

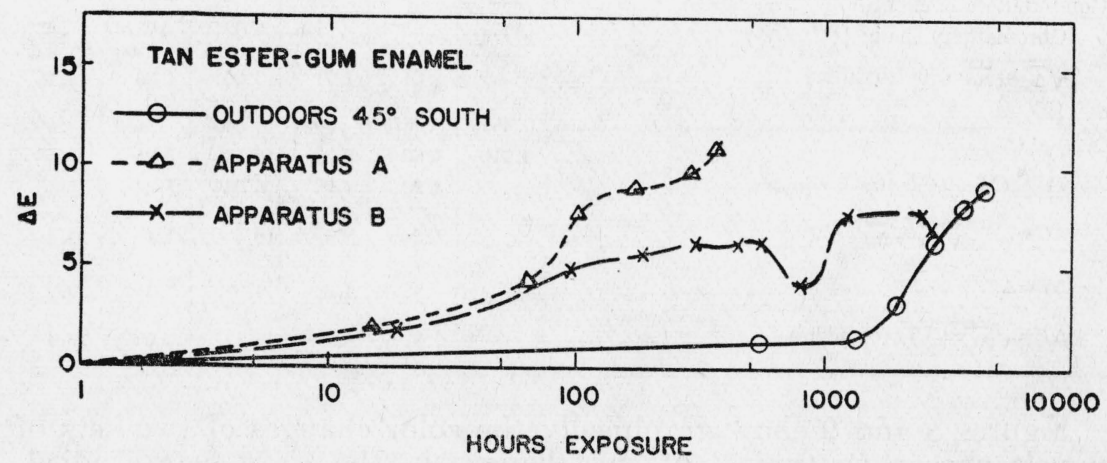

FIGURE 9.-Amounts of color change of the three tan ester-gum-enamel panels with length of exposure.

\section{SPECULAR GLOSS, $\mathrm{G}_{\mathrm{S}}$}

Measurement of the loss of specular gloss of an enamel-type paint finish provides a sensitive test of the deterioration of the surface. Specular reflection occurs at the air-paint interface of a paint film, and any mechanical change in the interface therefore affects the specular reflection of the film.

Figures 10 and 11 show graphically the changes of $45^{\circ}$ specular gloss during exposure of four of these six sets. The length of exposure is measured logarithmically as in figures 3,8 , and 9 so that the patterns of gloss change, which are similar except for the speed of change, 


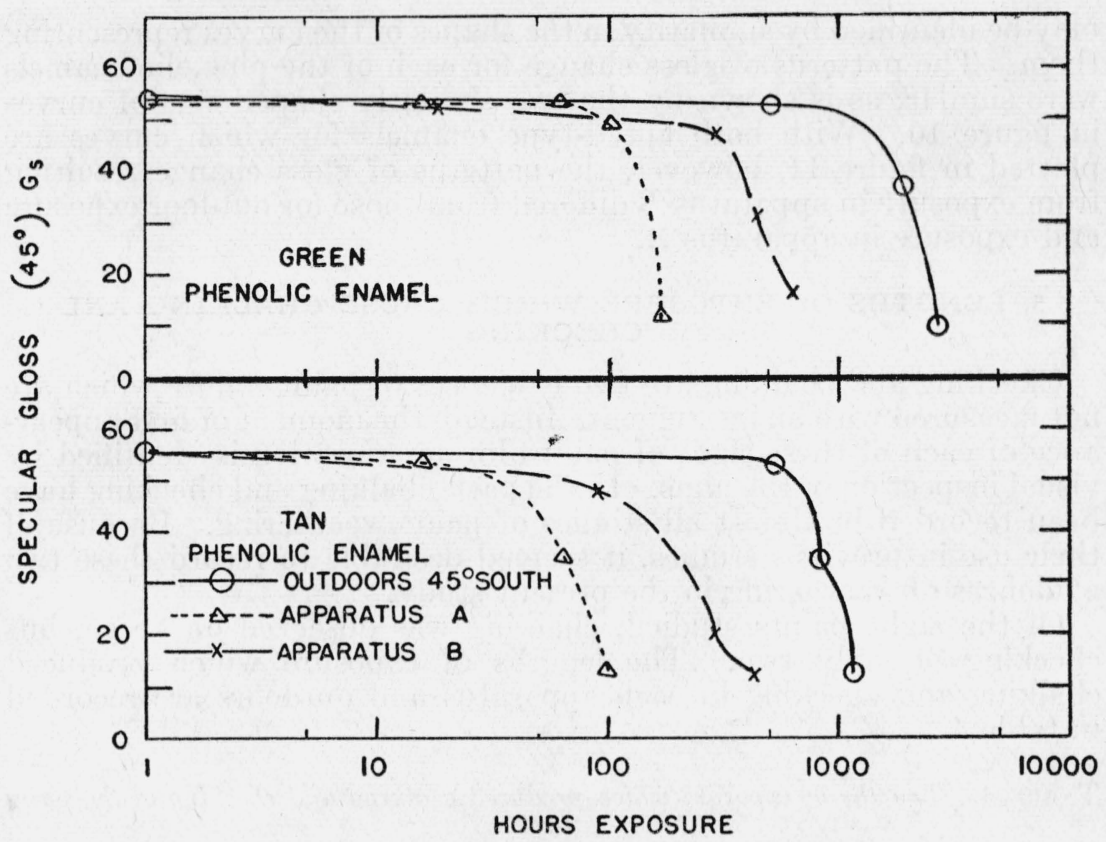

FIgURE 10.-Changes in the $45^{\circ},-45^{\circ}$ specular gloss of the six phenolic-enamel panels with length of exposure.

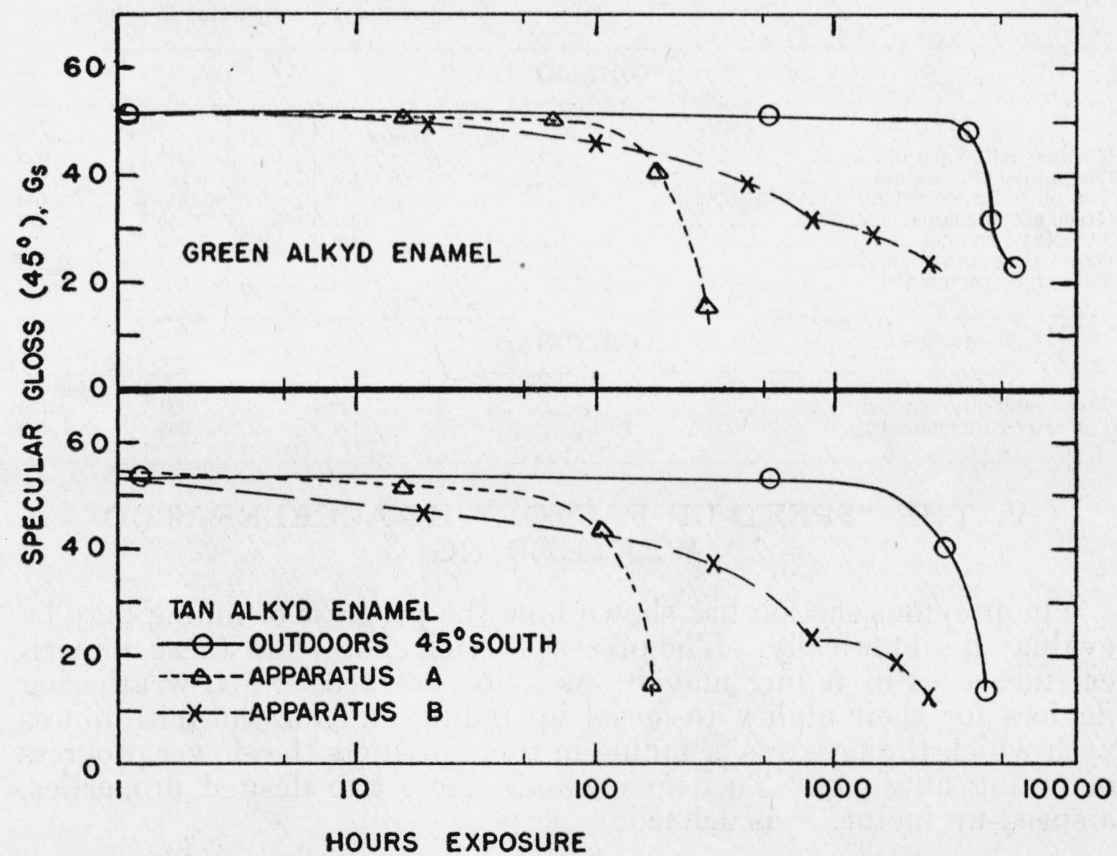

Figure 11.-Changes in the $45^{\circ},-45^{\circ}$ specular gloss of the six alkyd-enamel panels with length of exposure. 
may be identified by similarity in the shapes of the curves representing them. The patterns of gloss change for each of the phenolic enamels were similar, as is shown by the two similarly shaped sets of curves in figure 10. With both alkyd-type enamels for which curves are plotted in figure 11, however, the patterns of gloss change resulting from exposure in apparatus $B$ differed from those for outdoor exposure and exposure in apparatus $A$.

\section{LENGTHS OF EXPOSURE WHICH CAUSE CHALKING AND CHECKING}

Checking and chalking are two evidences of paint failure which are not measured with an instrument. Instead, the moment of first appearance of each of these signs of paint-film deterioration is identified by visual inspection of the films. In the past, chalking and checking have been recorded in almost all studies of paint weathering. Because of their use in previous studies, it seemed desirable to record these two evidences of weathering in the present study.

Of the eight paints studied, chalking was observed on seven, but checking on only two. The lengths of exposure which produced chalking and checking in each apparatus and outdoors are recorded in table 4 .

TABLE 4.-Lengths of exposure which produced chalking and checking of the paint finishes

\begin{tabular}{|c|c|c|c|}
\hline \multirow{2}{*}{ Paint finish } & \multicolumn{3}{|c|}{ Length of exposure } \\
\hline & Apparatus $A$ & Apparatus $B$ & Outdoors \\
\hline \multicolumn{3}{|l|}{ CHALKING } & 02 \\
\hline $\begin{array}{l}\text { Chrome-yellow paint } \\
\text { Green phenolic enamel } \\
\text { Tan phenolic enamel } \\
\text { Treen alkyd enamel } \\
\text { Tan alkyd enamel } \\
\text { Treen estergum enamel } \\
\text { Tan ester-gum enamel }\end{array}$ & $\begin{array}{r}\text { Hours } \\
272 \\
131 \\
82 \\
440 \\
161 \\
171 \\
171\end{array}$ & $\begin{array}{r}\text { Hours } \\
412 \\
550 \\
445 \\
2,400 \\
2,700 \\
303 \\
303\end{array}$ & $\begin{array}{r}\text { Hours } \\
1,920 \\
2,200 \\
2,160 \\
4,320 \\
4,320 \\
2,200 \\
1,440\end{array}$ \\
\hline \multicolumn{4}{|l|}{ CHECKING } \\
\hline $\begin{array}{l}\text { Green ester-gum enamel. } \\
\text { Tan ester-gum enamel }\end{array}$ & $\begin{array}{r}82 \\
171\end{array}$ & $\begin{array}{l}303 \\
303\end{array}$ & $\begin{array}{r}730 \\
1,440\end{array}$ \\
\hline
\end{tabular}

\section{THE "SPEED-UP FACTOR" IN ACCELERATED WEATHERING}

The previous section has shown how the progress of fading may be evaluated numerically. The present section shows how these numerical measures of fading may be used to rate accelerated-weathering devices for their ability to speed up fading and for the faithfulness with which the progress of fading in them predicts the slower progress of fading outdoors. To help evaluate these two desired properties, a speed-up factor, $F$, is defined:

$$
F \equiv \frac{\text { hours' exposure outdoors }}{\text { corresponding hours exposure in apparatus }}
$$


The magnitude of $F$ is thus the factor by which fading is speeded up. Constancy of $F$ through a course of fading indicates the faithfulness with which the fast fading in the apparatus predicts the course of slow fading outdoors.

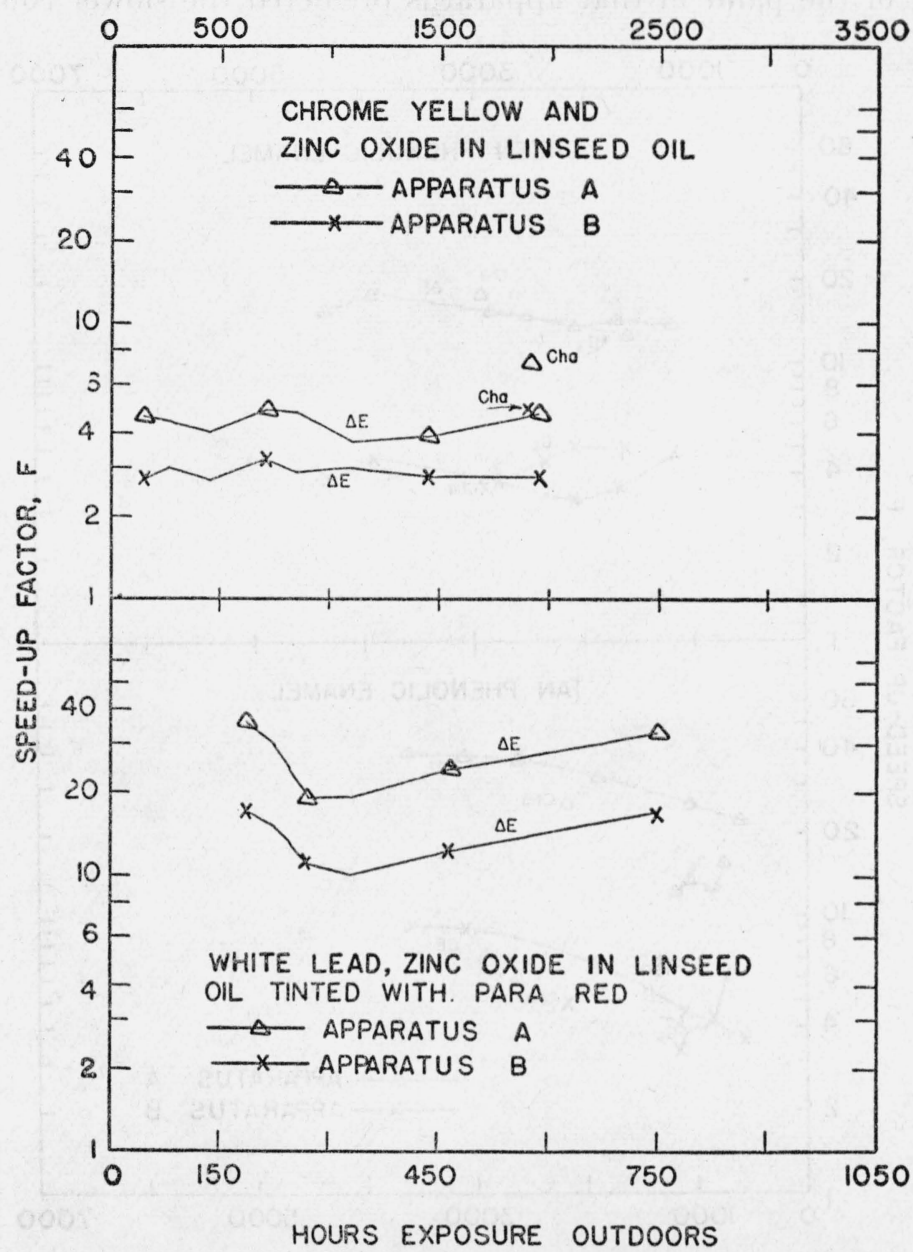

FIGURE 12.-The speed-up factor, $F$, for the apparatus exposures of the two linseedoil paint finishes plotted as a function of length of outdoor exposure producing the same change.

Color change, $\Delta E$; chalking, Cha.

Values of $F$ were computed from the measurements of color and gloss change and from the observed periods of exposure which produced chalking and checking. These values of $F$ have been plotted according to length of outdoor exposure in eight graphs, figures 12 through 15. In these graphs, the curves for color change are identified by $\Delta E$, those for specular gloss by $G_{\mathrm{s}}$, the points for chalking by $C h a$, and those for checking by Che. 
In the eight graphs showing values of $F$, the height of the points indicates speed-up of the apparatus-produced fading, and the degree to which the points for one apparatus approach a horizontal arrangement in a graph indicates the faithfulness with which the course of fading of the paint in that apparatus predicted the slower course of

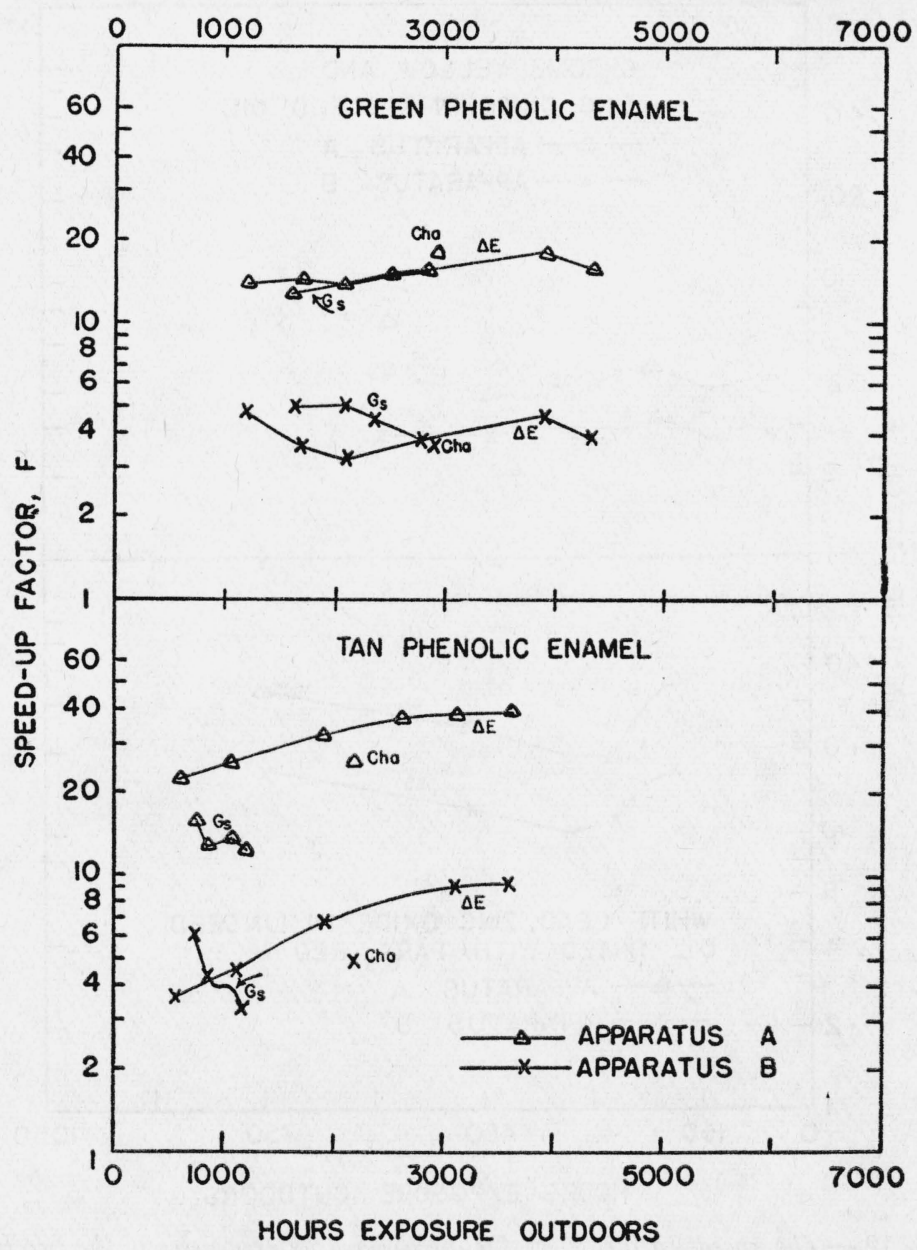

FIGURE 13.-The speed-up factor, $F$, for the apparatus exposures of the two phenolicenamel paint finishes plotted as a function of length of outdoor exposure producing the same changes.

Color change, $\Delta E$; gloss change, $G_{s}$; chalking, Cha.

fading outdoors. It is evident from inspection of the eight graphs that $F$ tends to change with both treatment and type of finish. Thus fading in apparatus $A$ averaged about 20 times as fast as fading outdoors, but it varied from about 5 times for the chrome yellow (fig. 12) to about 40 times for the tan ester-gum enamel (fig. 15). Fading in apparatus $B$ averaged about 5 times as fast as fading outdoors, but it 
varied from about 3 times for chrome yellow to about 20 times for the paint tinted with para red (fig. 12).

Inspection of the eight graphs reveals that the treatment of apparatus $A$ not only faded the paints faster, but it provided a preview of the course of fading which was, in general, a better representation

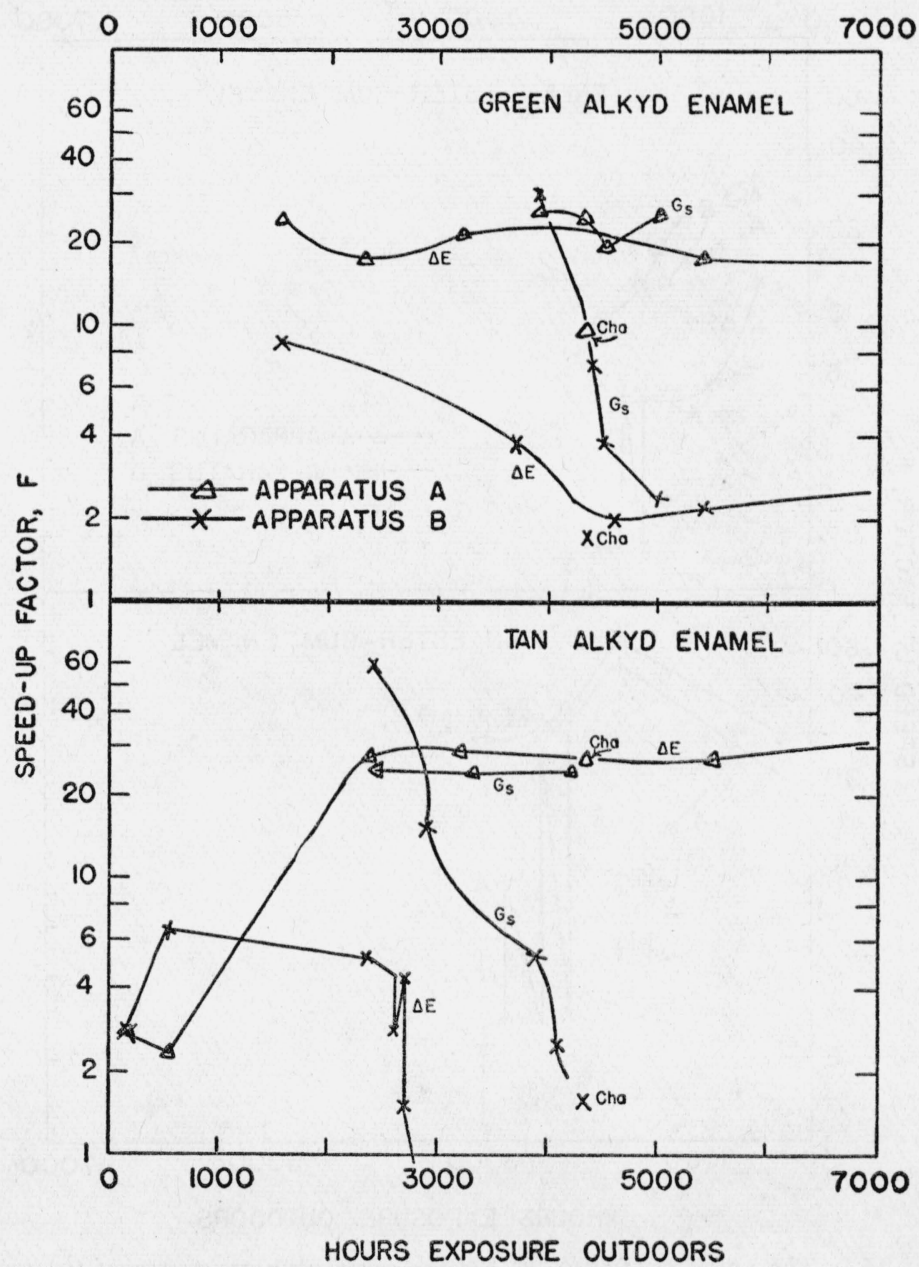

FIgure 14.-The speed-up factor, $F$, for the apparatus exposures of the two alkyd. enamel paint finishes plotted as a function of length of outdoor exposure producing the same changes.

Color change, $\Delta E$; gloss change, $G_{s}$; chalking, Cha .

of outdoor fading than that provided by the treatment of apparatus $B{ }^{5}$ However, the faithfulness of prediction, which is identified by the constancy of $F$, is seen by inspection of the eight graphs to vary markedly between finishes. The almost horizontal arrangements of

\footnotetext{
s It should be pointed out that the findings of the present study have no necessary connection with the relative merits of any accelerated-weathering devices on the market today. Apparatus $B$ was purchased 15 years ago and is not the model now sold by its manufacturer.
} 
the points representing the two linseed-oil paints and the green phenolic enamel finish in figures 12 and 13 , respectively, show fairly good predictions of the courses of outdoor fading with each apparatus. The points representing the tan phenolic enamel in figure 13 form somewhat less satisfactory approaches to the desired two horizontal

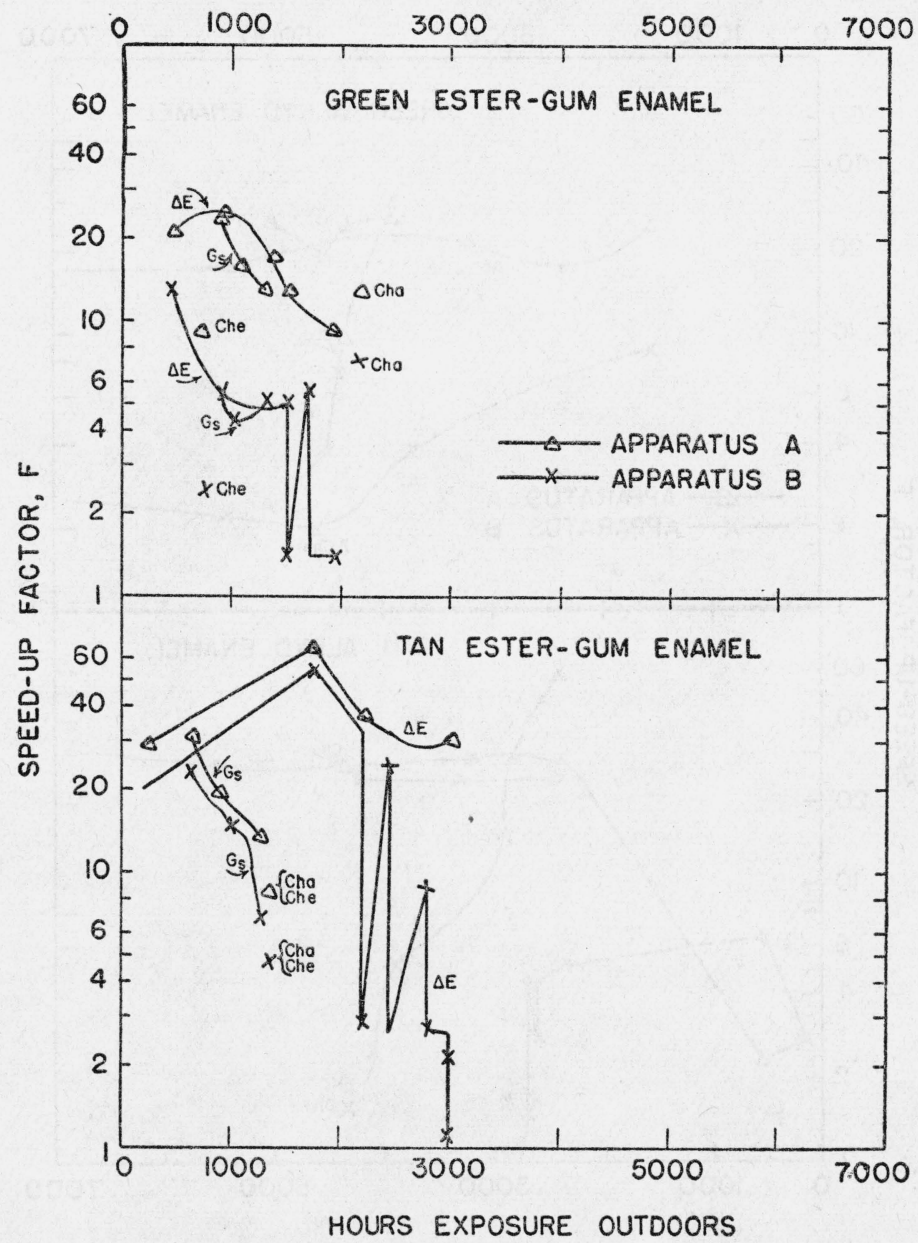

FIgure 15.-The speed-up factor, F, for the apparatus exposures of the two estergum-enamel paint finishes plotted as a function of length of outdoor exposure producing the same changes.

Color change, $\Delta E$; gloss change, $G_{\mathrm{s}}$; chalking, Cha; checking, Che.

arrangements, but they indicate more nearly constant values of $F$ than do most of the values shown in the remaining four graphs.

The treatment in apparatus $A$ was much superior to that in apparatus $B$ for predicting the courses of fading of the two alkyd enamels (fig. 14), even though the values of $F$ computed from amounts of color change for the first 2,000 hours of outdoor exposure of the tancolored enamel were inconstant. For the two phenolic enamels for 
which values of $F$ are represented in figure 15 , neither of the accelerated exposures predicted reliably the changes resulting from outdoor exposure; however, apparatus $A$ was again somewhat superior to apparatus $B$. Table 5 gives the range of values of $F$ found for each apparatus, for each paint finish, and for each of the types of change studied. There are also in this table a number of average values of $F$ estimated from inspections of the graphs, figures 12 through 15 .

TАВLE 5.-Limits of the values of $F$, the speed-up factor, for each treatment and for each of the finishes studied-from measurements of $\Delta E$, amount of color change; $G_{\mathrm{s}}$, specular gloss; Cha, initial chalking; Che, initial checking; and from all four causes

[In addition, estimated averages of $F$ were obtained by inspection of figures 12 through 15]

\begin{tabular}{|c|c|c|c|c|c|c|c|c|c|c|c|c|}
\hline \multirow{2}{*}{ Paint finish } & \multicolumn{5}{|c|}{$\begin{array}{l}\text { Limits of values of } F \text { for treat- } \\
\text { ment in apparatus } A \text {, derived } \\
\text { from values of- }\end{array}$} & \multirow{2}{*}{$\begin{array}{c}\text { Esti- } \\
\text { mat- } \\
\text { ed } \\
\text { aver- } \\
\text { age } \\
F\end{array}$} & \multicolumn{5}{|c|}{$\begin{array}{l}\text { Limits of values of } F \text { for treat- } \\
\text { ment in apparatus } B \text {, derived } \\
\text { from values of - }\end{array}$} & \multirow{2}{*}{$\begin{array}{l}\text { Esti- } \\
\text { mat- } \\
\text { ed } \\
\text { aver- } \\
\text { age } \\
F\end{array}$} \\
\hline & $\triangle E$ & $G_{8}$ & Cha & Che & All & & $\triangle E$ & $G_{s}$ & Cha & Che & All & \\
\hline $\begin{array}{l}\text { Chrome yellow, zinc ox- } \\
\text { ide, linseed oil. }\end{array}$ & 4 to 5 & & 7 & & 4 to 7 & 5 & & & 5 & & 3 to 5 & 3 \\
\hline Para red, linseed oil.... & 19 to 33 & & & & 19 to 33 & 27 & 10 to 17 & & & & 10 to 17 & 14 \\
\hline Phenolic resin, green & 14 to 18 & 13 to 15 & 17 & & 13 to 18 & 15 & 3 to 5 & 4 to 5 & 4 & & 3 to 5 & 4 \\
\hline Phenolic resin, tan & 22 to 39 & 12 to 16 & 26 & & 12 to 39 & 25 & 4 to 9 & 3 to 6 & 5 & & 3 to 9 & 5 \\
\hline Alkyd resin, green ...... & 17 to 24 & 20 to 26 & 10 & & 10 to 26 & 20 & 2 to 9 & 2 to 30 & 2 & & 2 to 30 & 4 \\
\hline Alkyd resin, $\tan$ & 3 to 34 & 24 to 26 & 27 & & 3 to 34 & 25 & 1 to 6 & 2 to 60 & 2 & & 1 to 60 & \\
\hline Ester-gum resin, green-- & 9 to 24 & 13 to 24 & 13 & 9 & 9 to 24 & 15 & 1 to 13 & 4 to 5 & 7 & 2 & 1 to 13 & 5 \\
\hline Ester-gum resin, tan.-.- & 30 to 65 & 13 to 31 & 8 & 8 & 8 to 65 & 30 & 1 to 33 & 7 to 23 & 5 & 5 & 5 to 33 & \\
\hline
\end{tabular}

Of possible interest here because of the different type of finish involved are some comparisons which were recently made between the periods of outdoor and apparatus exposures causing the failure of varnish films. Panels representing each of 16 oleoresinous varnishes were exposed outdoors and in each apparatus. The lengths of exposure which caused the first visible checking and then the checking which completely covered each panel were noted. The values of $F$ computed from these observed lengths of exposure of the 16 varnish films are of the same order of magnitude as the values given in table 5:

\begin{tabular}{|l|c|c|}
\hline \hline & $\begin{array}{r}F \text { - appara- } \\
\text { tus } A\end{array}$ & $\begin{array}{c}F \text { - appara- } \\
\text { tus } B\end{array}$ \\
\hline $\begin{array}{l}\text { First visible surface checking of 16 varnish films__ } \\
\text { Checking which covered panels of } 16 \text { varnish films }\end{array}$ & $\begin{array}{l}6 \text { to } 17 \\
8 \text { to } 16\end{array}$ & $\begin{array}{l}2 \text { to } 8 \\
3 \text { to } 10\end{array}$ \\
\hline
\end{tabular}

Since the present paper has been prepared chiefly to describe and demonstrate a method of evaluating fading, a detailed discussion of the factors in the accelerated exposures which were responsible for some of the unsatisfactory forecasts of natural fading is outside its scope. However, one of the factors causing poor prediction was probably the formation of chalk on the panel surfaces and the varying degrees to which it was removed by hard rains, wind, and dust erosion outdoors and by the rather vigorous spray used in one apparatus.

A note on the possible improvement of the exposure cycles used in the accelerating apparatus may be of interest. Paint finishes exposed 
outdoors in Washington, D. C., are periodically subjected to freezing temperatures and also to long periods of wetting. To simulate the effects of these periods, it is suggested that the panels be periodically removed from the accelerating apparatus, soaked in ice water for about 2 hours, and refrigerated for 2 or 3 hours at approximately $-15^{\circ} \mathrm{C}$. Preliminary trials with soaking and freezing once or twice a week in addition to ordinary exposure in the accelerating apparatus have shown considerable promise.

Furthermore, inconstancy of the values of $F$ should not be blamed altogether on the accelerated-exposure treatments. Outdoor weather varies markedly in its effect on paint finishes with place and direction of exposure, and with time of year. There is no standard outdoor weather, and a paint for general use must therefore be formulated to withstand strong irradiation from the sun at some places and times, intense cold at others, and strongly corrosive fumes at still others. The present tests relate only to the outdoor exposure of panels facing $45^{\circ}$ south on the roof of a building at the National Bureau of Standards. Comparisons of the results of the present accelerated exposures with other outdoor exposures might result in the finding of wholly different values of $F$ and wholly different degrees of faithfulness of predictions.

\section{CONCLUSIONS}

Methods of measuring and numerically specifying color change and gloss change have greatly improved within the past few years. The use of these methods to evaluate the fading of a material is now a much less tedious process than it would have been several years ago. The present paper has demonstrated how measurements made with certain instruments may be used to describe numerically the fading of a number of paint finishes and to compare numerically the fading of these finishes outdoors with that resulting from two treatments designed to produce this fading at a faster rate.

From these measurements it is possible to obtain a better picture of the progress of fading than has heretofore been available. $\mathrm{Nu}-$ merical studies of the type reported should be valuable aids to technologists seeking to improve the resistance of textiles and paint finishes to weathering. By comparing the progress of fading in accelerated tests and fading outdoors in the manner suggested, it should be possible to develop treatments for fading which give both greater speed of fading and improved accuracy for predicting the slower courses of outdoor fading. Improved accelerated-weathering apparatus will further help technologists in their attempts to improve the resistance of materials to weather.

\section{REFERENCES}

[1] Am. Soc. Testing Materials, Symposium on Correlation Between Accelerated Laboratory Tests and Service Tests on Protective Coatings. Booklet published by the American Society for Testing Materials, Philadelphia, Pa. (1937).

[2] Wm. D. Appel, Fading of dyeings in radiation of different intensities, Am. Dyestuff Reptr. 24, 306 (1935).

[3] Richard S. Hunter, Progress in developing a photoelectric method for measuring color difference, Bul. Am. Ceram. Soc. 18, 121 (1939).

[4] Richard S. Hunter, $A$ multipurpose photoelectric reflectometer, J. Research NBS 25, 581 (1940) RP1345; also J. Opt. Soc. Am. 30, 536 (1940). 
[5] Richard S. Hunter, Photoelectric Tristimulus Colorimetry, part of Symposium on Color, American Society for Testing Materials, Philadelphia, Pa. (1941).

[6] Richard S. Hunter, Photoelectric Tristimulus Colorimetry with Three Filters, NBS Circular C429 (1942).

[7] Deane B. Judd, Specification of color tolerances at the National Bureau of Standards, Am. J. Psychology 52, 418 (1939).

[8] Deane B. Judd, Specification of uniform color tolerances for textiles, Textile Research 9, 253, 292 (1939).

[9] D. B. Judd and K. L. Kelly, Method of designating colors, J. Research NBS 23, 355 (1939).

[10] Parry Moon, Proposed standard solar-radiation curves for engineering use, J. Franklin Inst. 230, 583 (1940).

[11] National Carbon Company, Radiation Characteristics, National Industrial and Therapeutic Carbons, Catalog Section A-4300 (National Carbon Co., Inc., Cleveland, Ohio, 1941).

[12] Francis Scofield, Method of Recording in Definite Percentages the Fading of Colors in Paints and Enamels, Sci. Sec. Cir. 566, Nat. Paint, Varnish \& Lacquer Assn., Inc., Washington, D. C. (1938).

[13] F. Scofield, D. B. Judd, and R. S. Hunter, A Proposed Method of Designating Color, ASTM Bul. 110, p. 19 (May 1941).

Washington, March 24, 1942. 